\title{
Monitoring Ectotrophic Root-lnfecting Fungi Associated with Bermudagrass Putting Green Roots Using Quantitative Multiplex Assays
}

\author{
Aline Bronzato-Badial, Jonas King, and Maria Tomaso-Peterson ${ }^{\dagger}$ \\ Department of Biochemistry, Molecular Biology, Entomology and Plant Pathology, Mississippi State University, Starkville, MS 39762
}

Accepted for publication 30 March 2020.

\begin{abstract}
Bermudagrass decline (BD) is a destructive root rot disease of hybrid bermudagrass putting greens in the southeastern United States. Previous studies reported a single ectotrophic root-infecting (ERI) fungus, Gaeumannomyces graminis, associated with BD. Recently, three novel ERI fungi, Gaeumannomyces sp., Magnaporthiopsis cynodontis, and Candidacolonium cynodontis, have also been associated with BD. Current diagnostic methods for identification can be inconclusive and inaccurate for distinguishing these ERI fungal species. Here, we present the development and application of novel real-time PCR assays designed to detect four selected ERI fungi associated with $B D$. The distribution of these ERI fungi in hybrid bermudagrass samples collected from putting greens and fairways throughout the southeastern United States was also assessed. In addition, we established a reliable and rapid protocol to simultaneously detect

lir

these selected fungi directly from bermudagrass root tissue. The limit of detection for each assay was as low as $1 \mathrm{pg} / \mu \mathrm{l}$ of DNA per reaction, proving the sensitivity of the method to detect low quantities of fungal DNA when present in bermudagrass roots. The presence of the selected ERI fungi was detected in 36 of 37 bermudagrass root samples, with one fungus having a wider distribution among the samples tested and two fungi with greater DNA quantities when compared with the bermudagrass roots. The novel assays provide a reliable method for accurate detection of the four selected ERI fungi. The acute sensitivity of each assay makes it a viable tool for early detection of ERI fungi in hybrid bermudagrass roots.

Keywords: hybrid bermudagrass, ectotrophic root-infecting fungi, rapid detection, multiplex assays
\end{abstract}

Bermudagrasses (Cynodon dactylon L.) and hybrid bermudagrasses including ultradwarf bermudagrasses (UDBs) (Cynodon dactylon L. $\times$ Cynodon transvaalensis Burtt-Davy) are common putting green grasses in golf courses in the southern United States (Turgeon 2005).

Bermudagrass decline (BD) is considered a destructive disease of UDB putting greens with symptoms appearing as irregularly shaped chlorotic patches along the margins of putting greens due to significant root rot (Freeman and Augustin 1984). Symptoms of BD are present during the late summer and early fall in the southeastern United States, when the temperature and humidity are consistently high and precipitation occurs almost daily (Elliott and Landschoot 1991; Smiley et al. 2005). Associated with BD is the presence of ectotrophic root-infecting (ERI) fungi that are responsible for causing root rot in bermudagrasses.

${ }^{\dagger}$ Corresponding author: M. Tomaso-Peterson; mariat@pss.msstate.edu

Funding: Funding for this work was provided by the Mississippi Agricultural and Forestry Experiment Station, the National Institute of Food and Agriculture, U.S. Department of Agriculture, Hatch project under accession number 213130.

*The $e$-Xtra logo stands for "electronic extra" and indicates that two supplementary figures are published online.

The author(s) declare no conflict of interest.

C 2020 The American Phytopathological Society
These fungi comprise several genera of soil-borne, necrotrophic pathogens, and when active in bermudagrasses they cause circular or patch-like symptoms and rotted roots (Clarke and Gould 1993; McCarty and Lucas 1989). To date, Gaeumannomyces graminis (Sacc.) Arx \& Oliver (Gg) in the family Magnaporthaceae is the only recognized causal agent of BD (Elliott 1991). Vines (2015) used morphological, biological, and phylogenetic analyses to characterize three novel ERI fungi, also residing in the Magnaporthaceae family. Pathogenicity evaluations showed these novel ERI fungi are parasitic to UDB roots, causing root rot. Vines (2015) also suggested that collectively with $\mathrm{Gg}$, the novel species form an infection complex with simultaneous presence of these four fungi in bermudagrass roots.

Traditionally, ERI fungal detection is based on foliar and root symptoms in the turf, and confirmation is based on the characteristic structures unique to ERI fungi. ERI fungi produce dark ectotrophic runner hyphae and growth cessation structures on plant roots, and webbed mycelium with simple or lobed hyphopodia can be observed on stolons, roots, and rhizomes (Landschoot 1993). Prior to Vines's work in 2015, Gg was the only ERI fungus known to produce deeply lobed hyphopodia, and all other ERI fungi were indistinguishable. This made diagnosis difficult and, in many cases, resulted in inaccurate or inconclusive identification.

Various molecular techniques have been used to identify ERI fungal species within Magnaporthaceae when present in bermudagrass roots (Elliott et al. 1993; Freeman and Ward 2004; Rachdawong et al. 2002; Sadeghi et al. 2012; Ward and Akrofi 
1994; Wetzel et al. 1996). However, in cases of multifungal presence, the differentiation of fungi by existing molecular methods is inadequate. Considering that bermudagrass management of $\mathrm{BD}$ is focused on preventative methods, and pathogen infection and spread usually occurs months before foliar symptoms are observed, accurate and early detection of ERI fungi play an important role in disease prevention.

This research focused on the development of four novel real-time polymerase chain reaction (PCR) assays and their application for the early detection of ERI fungi in bermudagrass root samples. The assays are based on locked nucleic acid (LNA) probe technology, which, in this case, increased specificity and enabled ERI fungal detection directly from root samples. The assays are also very sensitive and can detect very low amounts of ERI fungal DNA. This characteristic allows its application as a tool for the early detection of pathogens in areas that have no symptoms of ERI fungal presence. In addition, these assays are considered low cost because of their use in multiplex reactions, downscaling the costs for reagents and accelerating the detection process.

\section{Materials and Methods}

Single and multiplex assays for the detection and differentiation of selected ERI fungi. Fungal isolates and identification.

The ERI fungi used in this study include isolates of Gg DR12-1 and

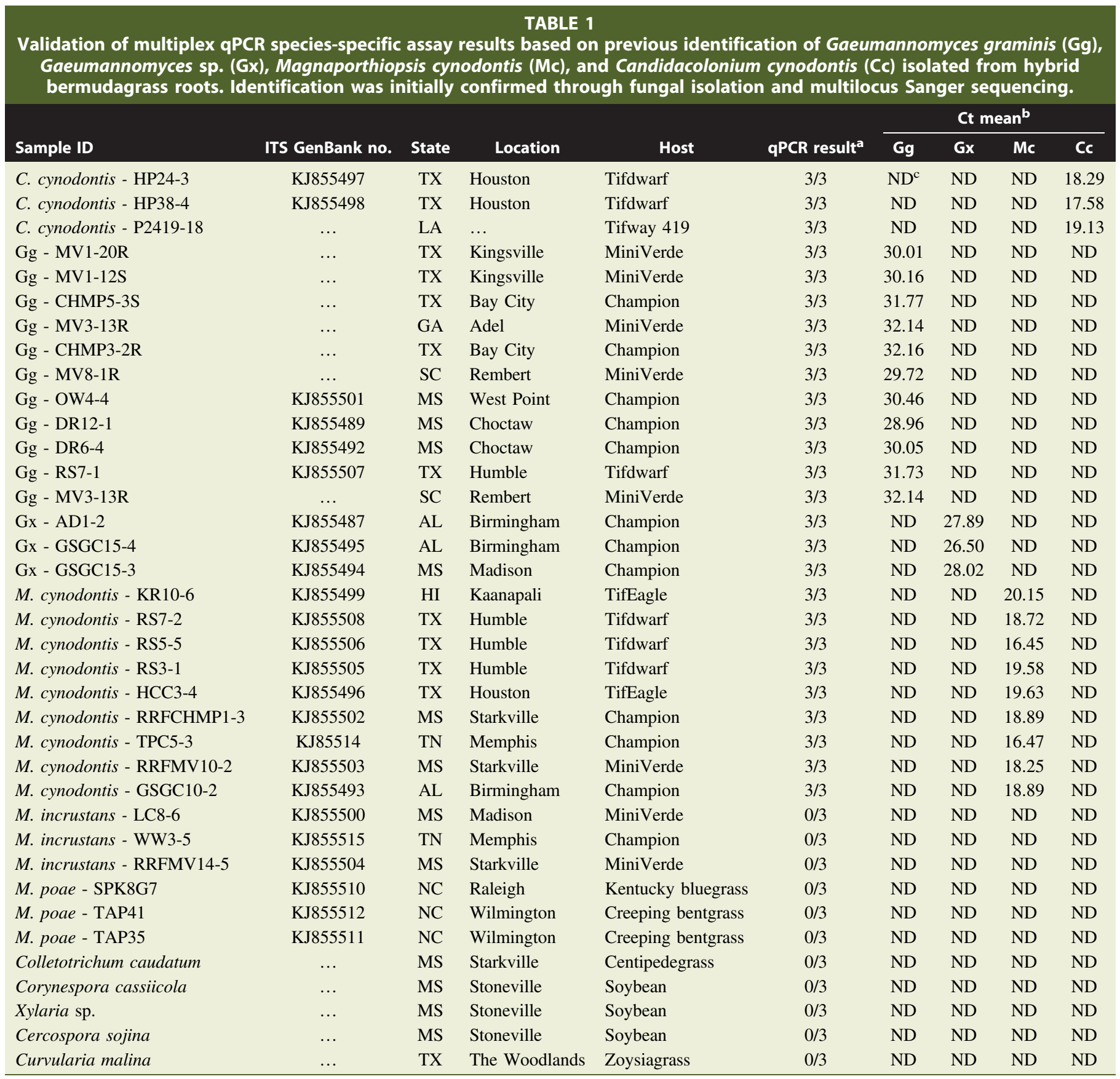

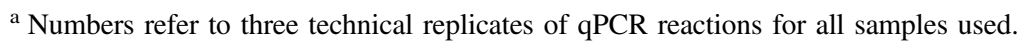

${ }^{\mathrm{b}} \mathrm{Ct}$ mean $=$ mean of cycle threshold values for positive amplification.

${ }^{\mathrm{c}} \mathrm{ND}=$ samples not detected by the assays. 
three novel ERI fungi: Magnaporthiopsis cynodontis TPC5-3 (Mc) (Vines et al. 2020) and undescribed species of both Gaeumannomyces sp. GSGC15-4 (Gx) and Candidacolonium cynodontis HP38-4 (Cc) (Table 1). These fungi were originally isolated from Tifdwarf and UDB roots ('Champion', 'TifEagle', and 'MiniVerde') collected in 2012 from four different states in the southern United States. Fungal isolates were retrieved from long-term storage and grown on potato dextrose agar (PDA) (Fisher Scientific, Hampton, NH) at $26^{\circ} \mathrm{C}$ in the dark for 2 weeks (Young et al. 2010). DNA isolation of fungal mycelium was conducted using the Fungi/Yeast Genomic DNA Isolation Kit (Norgen Biotek, Thorold, ON, Canada) following the manufacturer's protocol. To confirm fungal identity, the ITS15.8S-ITS2 nuc rDNA internal transcribed spacer (ITS) was amplified using ITS4 and ITS5 primers, as previously described by White et al. (1990). Amplification reactions were performed with GoTaq PCR Core Systems (Promega, Madison, WI) in a MyCycler Thermal Cycler (Bio-Rad Laboratories, Hercules, CA) using cycling conditions described by Zhang et al. (2011). After confirmation of amplicon size on a gel, amplified PCR products were cleaned using ExoSAP-IT (Affymetrix, Santa Clara, CA) and sequenced through MWG Operon (Eurofins Genomics, Huntsville, AL).

Design of primers and probes. Four LNA quantitative real-time PCR (qPCR) assays were developed based on fungal DNA sequences available at NCBI. The minichromosome maintenance complex component - 7 (MCM7) gene sequence was used as a reference to design primers and species-specific probes for Gg (GenBank KP007338), Gx (GenBank KP007342), and Mc (GenBank $\mathrm{KP} 007356)$, and the largest subunit of RNA polymerase II $(R P B 1)$ was the reference to design primers and probe for $\mathrm{Cc}$ (GenBank KP268920) (Table 2). Gx-LNA probe was labeled with hexachlorofluorescein (HEX) at the $5^{\prime}$ end and with Iowa Black FQ quencher (IDT, Coralville, IA) at the $3^{\prime}$ end. Gg-LNA probe was labeled with 6-carboxyfluorescein (6-FAM) at the $5^{\prime}$ end and with Iowa Black FQ quencher (IDT) at the $3^{\prime}$ end. Mc-LNA probe was labeled with Yakima Yellow at the $5^{\prime}$ end and with Iowa Black FQ quencher (IDT) at the $3^{\prime}$ end. Finally, Cc-LNA probe was labeled with 6-FAM at the $5^{\prime}$ end and with Iowa Black FQ quencher (IDT) at the $3^{\prime}$ end (Table 2). The $M C M 7$ and RPBI genes were selected to design the ERI primers and probes because they showed the most appropriate level of distinction across all four fungi species. A bermudagrass primer and probe set was designed to test interference of plant DNA material on the fungal assay's performance and determine the absolute quantity of fungal versus plant in infected samples. To amplify genetic material of bermudagrass samples, we characterized a partial nucleotide sequence of the translation elongation factor 1-alpha (Efl- $\alpha)$ of $C$. dactylon. Efl- $\alpha$ gene sequences from individuals of the Poaceae family, Zea mays L. (GenBank NM_001112117.2), Saccharum officinarum L. (GenBank EF581011.1), Eleusine indica L. (GenBank KU720633.1), Hordeum vulgare L. (GenBank AK250680.1), and Triticum aestivum L. (GenBank AK334915.1) were aligned using MEGA6 software (Tamura et al. 2013), and a forward and reverse primer set was designed based on a conserved region across all five species (Table 2). The bermudagrass $E f l-\alpha$ target region was amplified by conventional PCR using GoTaq PCR Core Systems (Promega), and the amplicons were visualized in $1 \%$ agarose gel stained with ethidium bromide (Sigma-Aldrich, St. Louis, MO). Amplicons were treated with ExoSAP-IT (Affymetrix) and submitted to Eurofins Genomics (Louisville, KY) for Sanger sequencing. This procedure was repeated for four different varieties within hybrid bermudagrass to confirm the accuracy of the amplified region matching the $C$. dactylon Ef1- $\alpha$ region. The obtained EfI- $\alpha$ partial gene sequence was used as a reference to design the bermudagrass qPCR assay primer set and probe. The bermudagrass EfI- $\alpha$ TaqMan probe was labeled with tetramethylrhodamine (TAMRA) at the $5^{\prime}$ end and with Iowa Black RQ (IDT) at the $3^{\prime}$ end (Table 2).

Real-time PCR conditions. Real-time PCR amplification conditions were optimized for each assay in single PCR reactions and later optimized to function in multiplex reactions. Single reactions were composed of a primer set and a species-specific probe, whereas multiplex assays were organized by combining $\mathrm{Gg}, \mathrm{Gx}$, and bermudagrass in one reaction, and $\mathrm{Mc}, \mathrm{Cc}$, and bermudagrass

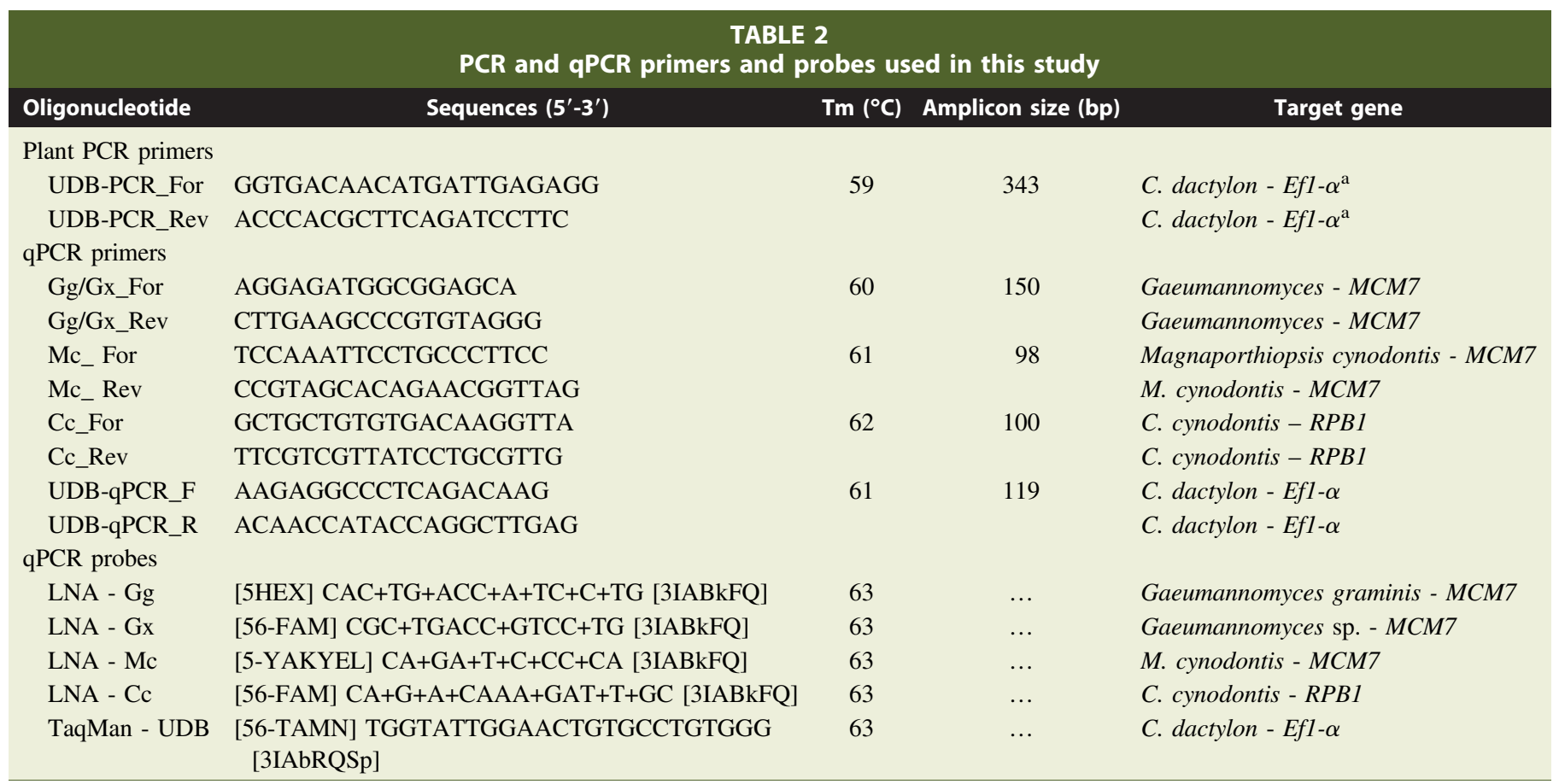

${ }^{a}$ Bermudagrass (Cynodon dactylon) (ultradwarf bermudagrass [UDB]) Ef1- $\alpha$ gene sequence characterized in this study. 
in a second multiplex reaction. All reactions were carried out using a StepOne Plus Real-Time PCR System (Applied Biosystems, Foster City, CA). Both single and multiplex reactions were performed in a total volume of $20 \mu \mathrm{l}$ containing $1 \mu \mathrm{l}$ of template DNA, $250 \mathrm{nM}$ of the probe, and $12.5 \mu \mathrm{l}$ of $(2 \times)$ Maxima Probe qPCR Master Mix (Thermo Fisher Scientific, Waltham, MA). Primer concentrations varied from $150 \mathrm{nM}$ of forward and reverse primers for $\mathrm{Cc}, \mathrm{Mc}$, and bermudagrass assays to $200 \mathrm{nM}$ of forward and reverse primers for $\mathrm{Gg}$ and Gx. Optimal thermal cycling conditions were $95^{\circ} \mathrm{C}$ for $10 \mathrm{~min}$ and 40 cycles of $95^{\circ} \mathrm{C}$ for $15 \mathrm{~s}$ and $63^{\circ} \mathrm{C}$ for $1 \mathrm{~min} 30 \mathrm{~s}$. Assay sensitivity and specificity. To determine the sensitivity of assays in single and multiplex reactions, 10-fold serial dilutions of DNA were prepared and amplified using the qPCR conditions described above. Samples used included axenic fungal culture DNA of $\mathrm{Gg}, \mathrm{Gx}, \mathrm{Mc}$, and $\mathrm{Cc}$, and DNA from noninfected bermudagrass root material. A consistent amplification of replicates determined the limit of detection (LOD) at the lowest amount of DNA at the end of each standard curve. Assay efficiencies were calculated for single and multiplex reactions according to the following formula: $\mathrm{E}=$ $[(10(-1 /$ slope $))-1) \times 100]$. To confirm the specificity of each assay to its target fungus we challenged the assays with DNA extracted from five nonrelated soil-borne fungi. Cross-amplification between the four ERI fungi was also tested by spiking nontarget fungal DNA in PCR reactions. In total, 11 different DNA samples of $\mathrm{Gg}$, three of $\mathrm{Gx}$, nine of Mc, and three of $\mathrm{Cc}$ were tested (Table 1). To verify that cross-reactivity was not occurring between the fungal and bermudagrass root probes in multiplex reactions, a constant known quantity of the bermudagrass root DNA $(50 \mathrm{ng} / \mu \mathrm{l})$ was spiked on each fungal reaction.

Pathogen versus plant quantification. Plasmids containing the target sequences were made to create a standard curve to quantify the absolute number of copies of each fungus versus bermudagrass root DNA in field-collected samples. DNA from $\mathrm{Gg}, \mathrm{Gx}, \mathrm{Mc}, \mathrm{Cc}$, and noninfected bermudagrass root samples was obtained as previously described and the primer region amplified using the real-time PCR assays. For each fungus and root, a plasmid was generated using the pMiniT 2.0 vector (NEB PCR cloning kit) (New England Biolabs, Ipswich, MA) following the manufacturer's protocol. Briefly, PCR products were purified using the PCR purification kit (Invitrogen, Waltham, MA), inserted into the pMiniT 2.0 vector and were transformed into 10-beta Escherichia coli competent cells (New England Biolabs). Colonies were screened via PCR, and positive colonies were incubated in liquid Luria broth at $37^{\circ} \mathrm{C}$ overnight to expand the number of colonies carrying the target DNA. Thereafter, cloned plasmids were purified using a mini-prep kit (Qiagen, Germantown, MD) and sequenced to confirm the identity of each insert. Plasmids were linearized using the exonuclease Aat1 (New England Biolabs) and the concentration measured via Nanodrop spectrophotometer. The number of copies of each plasmid was determined using the following equation: number of copies = \{plasmid $[\mathrm{mg} / \mu \mathrm{L}] \times 10^{-8} /($ plasmid + insert $(\mathrm{bp}) \times 660) \times 6.022 \times$ $\left.10^{23}\right\}$. The initial concentration of each plasmid was adjusted in nuclease-free water to $10^{10}$ copies/ $\mu 1$, and subsequently a 10 -fold serial dilution was prepared in duplicate to establish the LOD for each target assay on single and multiplex reactions. Cycle threshold $(\mathrm{Ct})$ values from each positive field-collected sample run in the multiplex reaction were interpolated on plasmid standard curves to estimate the number of copies of fungus and plant.

Application of multiplex assays in field-collected bermudagrass samples. Hybrid bermudagrass samples throughout the southeastern United States were submitted to the Plant Disease Diagnostics Laboratory at Mississippi State University for disease diagnostic examination in 2018. In general, the samples comprised dark and discolored roots interspersed with healthier roots. Total gDNA was extracted from the roots of 37 hybrid bermudagrass samples. Soil and organic plant debris were washed using distilled water. Roots were removed at the crown on the stolon using scissors. Detached roots were rinsed in a $2.5 \%$ sodium hexametaphosphate (The Chemistry Store, St. Cayce, SC) solution. Roots were dried on filter paper in a biosafety cabinet (LabConco, Kansas City, MO), and a total of $1.5 \mathrm{~g}$ of root material was used to extract DNA using the DNeasy Power Soil kit (Qiagen) based on the manufacturer's instructions. The obtained gDNAs were tested using multiplex assays developed in this study. The DNA concentration of all samples was adjusted with nuclease-free water to $2 \mathrm{ng} / \mu \mathrm{l}$ prior to PCR runs. Each sample was tested in duplicate and considered positive for ERI fungal presence when both duplicates showed PCR amplification and Ct values were equal or lower than 35 . The number of DNA copies was calculated as previously described, and the total DNA copy number was used to compare the amount of bermudagrass root versus fungal DNA for each sample. Dunn's test (Dunn 1961) was applied for means comparison using Bonferroni correction $(P<0.05)$.

\section{Results}

Single and multiplex assays for the detection and differentiation of selected ERI fungi. Single and multiplex reaction assays
A

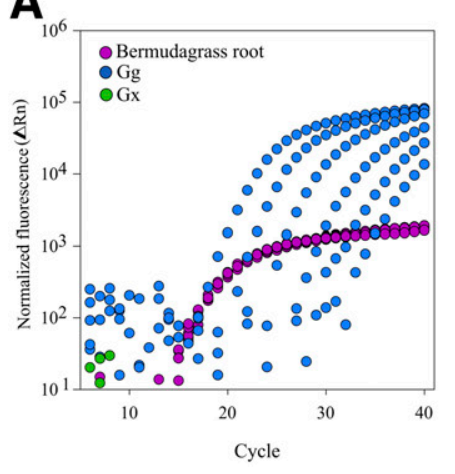

B

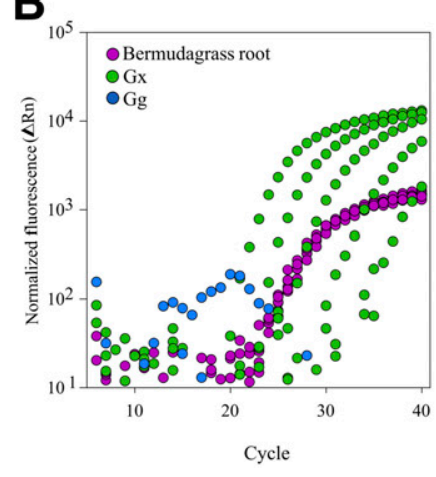

C

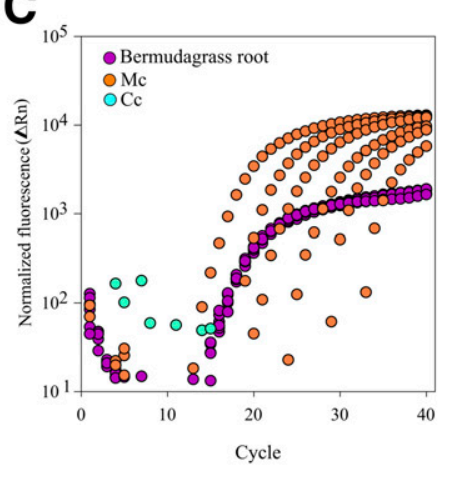

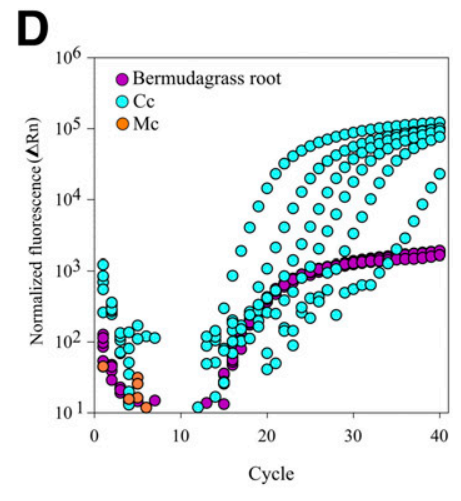

FIGURE 1

Specificity of assays. Serial dilution of fungal assays versus constant concentration ( $50 \mathrm{ng} / \mu \mathrm{l})$ of bermudagrass root DNA. A, Gaeumannomyces graminis (Gg) versus root; B, Gaeumannomyces sp. (Gx) versus root; C, Magnaporthiopsis cynodontis (Mc) versus root; and D, Candidacolonium cynodontis (Cc) versus root. Fluorescent signal is only captured from assays when template DNA is present in the reaction. 
designed to amplify DNA of the four selected ERI fungi resulted in consistent amplification at very low amounts of target DNA with LODs equal to $1.0 \mathrm{pg} / \mu \mathrm{l}(\mathrm{Gg}[\mathrm{Ct}=36], \mathrm{Gx}[\mathrm{Ct}=35], \mathrm{Mc}[\mathrm{Ct}=35]$, and $\mathrm{Cc}[\mathrm{Ct}=35]$ ) (Supplementary Fig. S1). Design of the bermudagrass $E f 1-\alpha$ forward and reverse PCR primers was done based on a conserved region of the $E f I-\alpha$ gene of the selected individuals of the Poaceae family. After confirmation of the bermudagrass Ef1- $\alpha$ gene region by traditional PCR and Sanger sequencing
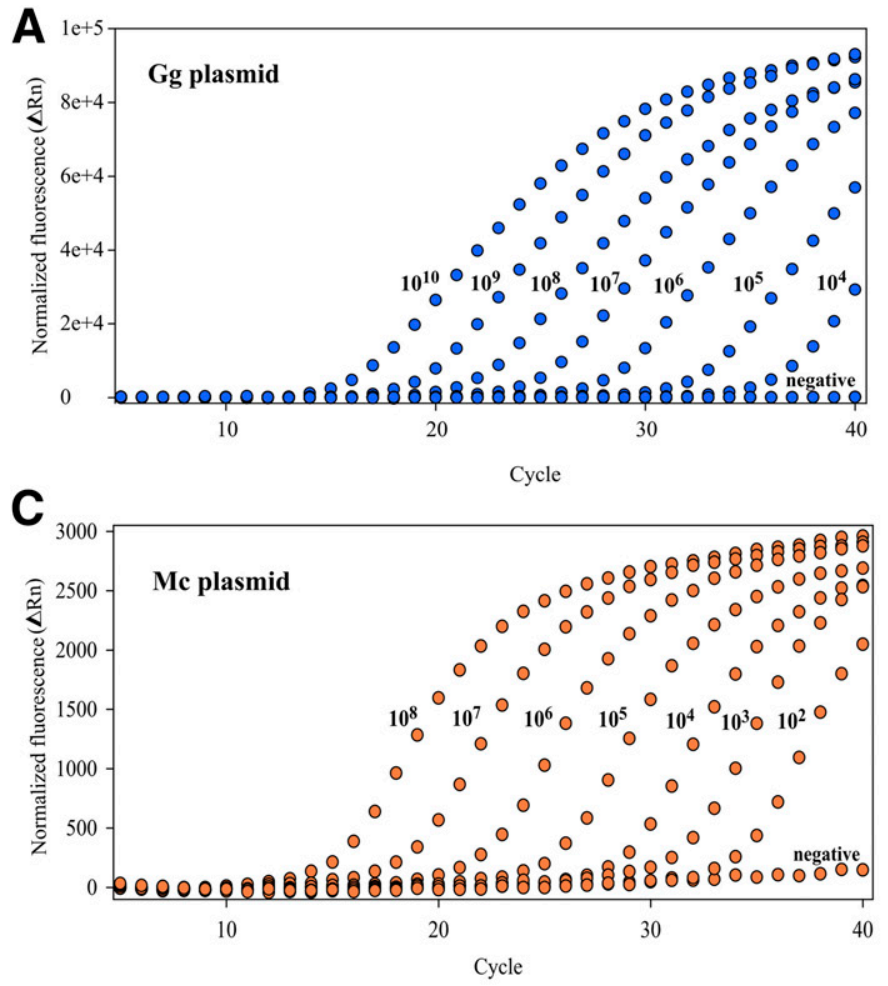

$\mathbf{E}$

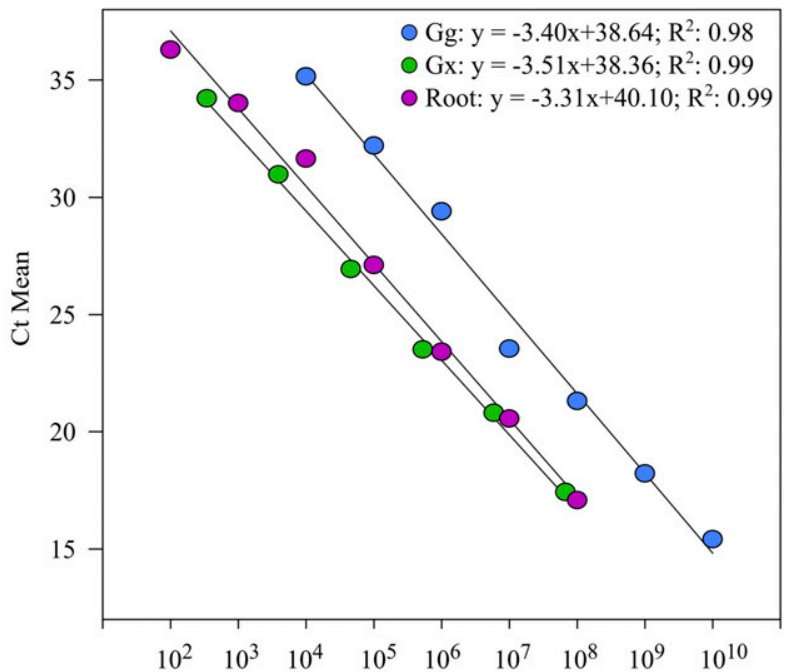

Plasmid $\log 10$ dilution
(Supplementary Fig. S2A), the obtained nucleotide sequence was used as a template to design the bermudagrass root real-time forward and reverse primers and probe. The bermudagrass qPCR assay showed LOD equal to $10 \mathrm{pg} / \mu \mathrm{l}(\mathrm{Ct}=36)$ and efficiencies and linearity of amplification around $100 \%\left(\mathrm{E}=100 \%\right.$ and $\left.R^{2}=0.99\right)$ (Supplementary Fig. S2B). PCR amplicons also showed consistent efficiency amplification rates in both single and multiplex reaction settings $(\sim \mathrm{E} \geq 93 \%)$ with a high linearity correlation coefficient
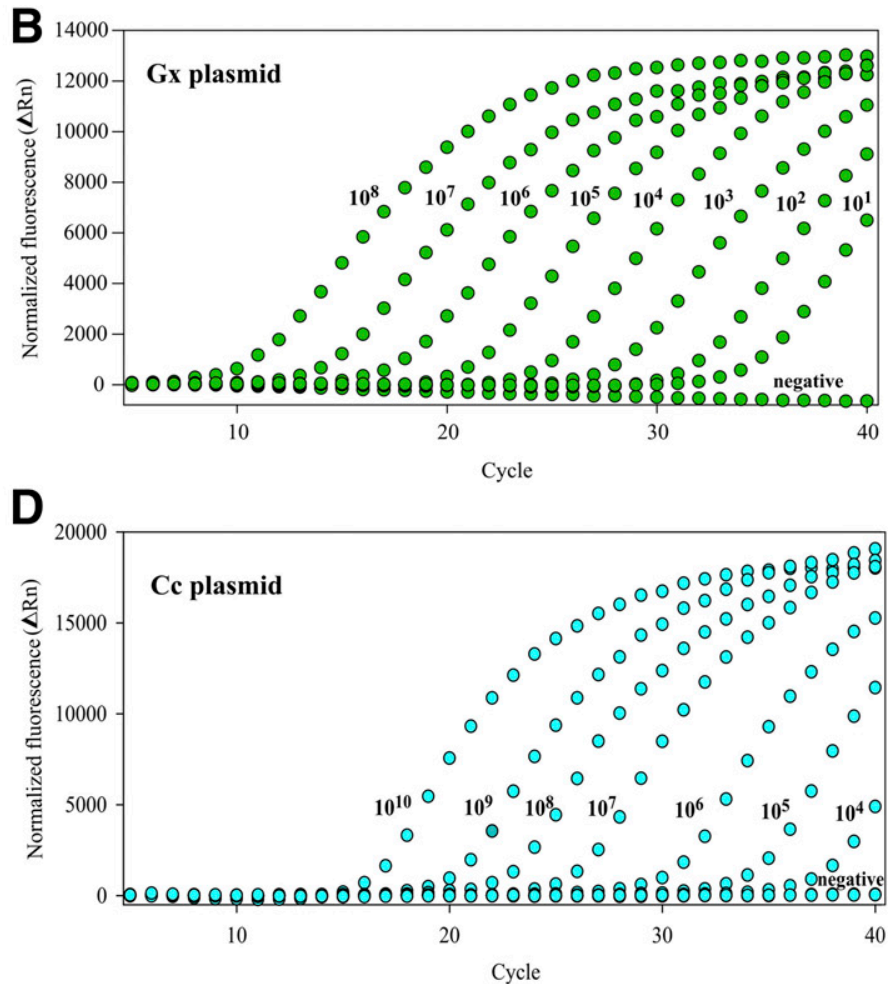

$\mathbf{F}$

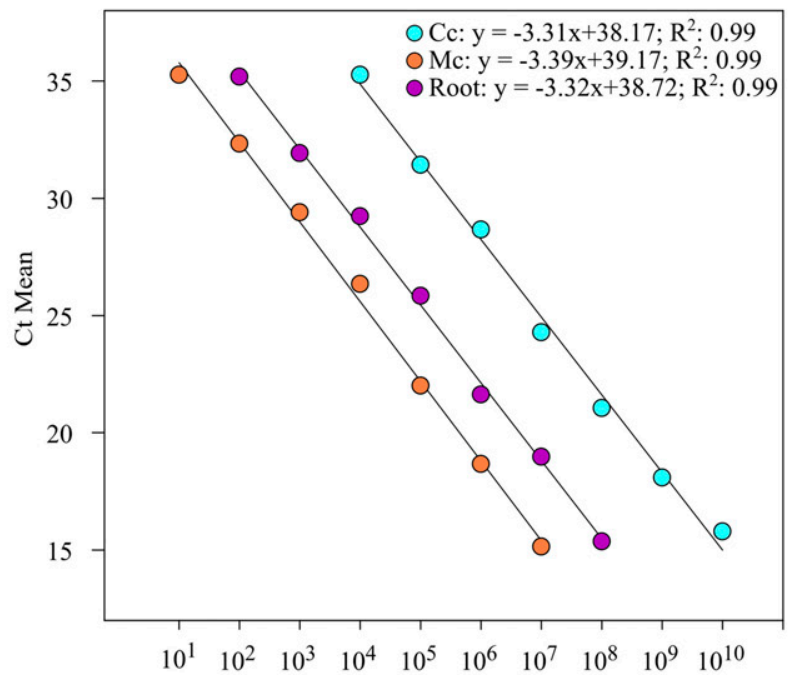

Plasmid $\log 10$ dilution

FIGURE 2

Plasmid standard curves for calculating number of DNA copies. Plasmid DNA was serially diluted, and the limit of detection (LOD) adjusted for each target plasmid. A, Gaeumannomyces graminis (Gg) plasmid, LOD $=10^{4} ; \mathbf{B}$, Gaeumannomyces sp. (Gx) plasmid, LOD =10 ${ }^{1}$; C, Magnaporthiopsis cynodontis (Mc) plasmid, $\mathrm{LOD}=10^{2} ; \mathbf{D}$, Candidacolonium cynodontis (Cc) plasmid, LOD $=10^{4} ; \mathbf{E}$, standard curves of $\mathrm{Gg}$, Gx, and bermudagrass root plasmids in multiplex I (efficiencies: $\sim 100 \%$ for all three targets); and $\mathbf{F}$, standard curves of Cc, Mc, and bermudagrass root plasmids in multiplex II (efficiencies: $\sim 100 \%$ for all three targets). 
$\left(\sim R^{2} \geq 0.98\right)$ (Supplementary Fig. S1). All fluorescent signals were correctly captured, resulting in an accurate identification of the target fungus when present in the reaction (Fig. 1). Specifically, the Gx assay, represented by the green dots, showed no amplification when the template DNA was not added to the reaction (Fig. 1A). In the same way, when the Gg template is not present in the reaction, no amplification is observed (Fig. 1B). In the second multiplex reaction for $\mathrm{Mc}, \mathrm{Cc}$, and bermudagrass roots, Mc DNA is only amplified when the target DNA is present in the reaction (Fig. 1C); in turn, Cc was only amplified when template DNA was added to the reaction (Fig. 1D). The purple curve, which represents the bermudagrass root DNA, produced a consistent pattern of amplification in both multiplex reactions (Fig. 1). These results indicate that the presence of the root DNA does not interfere with the performance and specificity of each assay. When assays were challenged against a panel of nontarget soil-borne fungi, amplification was not detected, including closely related species such as $M$. poae and $M$. incrustans, therefore validating the specificity of the four assays to their target fungus (Table 1).

Pathogen versus plant quantification. Efficiencies and linearity of plasmids were tested to assess the consistency of amplification and accurate quantification of fungal and bermudagrass root DNA in PCR reactions. There was a negative correlation between $\mathrm{Ct}$ values and $\log ^{10}$ of the initial known plasmid quantities $\left(R^{2} \sim 0.99\right)$ over a range of the number of copies in nanogram quantities of each assay, suggesting a strong linear relationship between target plasmidDNA concentrations and $\mathrm{Ct}$ values (Fig. 2). Plasmid DNA samples were tested in single and multiplex reactions, and the LOD of each fungal-plasmid DNA was established at $10^{4}$ copies $/ \mu \mathrm{l}$ for $\mathrm{Gg}(\mathrm{Ct}=$ 34), $10^{1}$ copies $/ \mu \mathrm{l}$ for $\mathrm{Gx}(\mathrm{Ct}=35), 10^{2}$ copies $/ \mu 1$ for $\mathrm{Mc}(\mathrm{Ct}=35)$, and $10^{4}$ copies $/ \mu$ for $\mathrm{Cc}(\mathrm{Ct}=35)$, and the bermudagrass rootplasmid DNA was established at $10^{2}$ copies/ $\mu \mathrm{l}(\mathrm{Ct}=35)$ (Fig. 2). Similar $\mathrm{Ct}$ values, efficiencies, and linearity were observed for all representative plasmids in single and multiplex reactions ( $\mathrm{E} \geq 93 \%$; $R^{2} \sim 0.99$ ) (Fig. 2).

Application of multiplex assays in field-collected bermudagrass samples. The multiplex assays were successful in detecting and differentiating the selected ERI fungi within the bermudagrass root gDNA samples. Out of 37 samples, 36 were positive for at least one ERI fungus. Mc was detected in all samples except the sample from Arkansas. Gg was detected in samples from Alabama, Mississippi, Tennessee, and Texas. Cc was present in samples from Alabama, Louisiana, Mississippi, and Texas, and Gx was present in samples from Louisiana, Mississippi, and Tennessee (Fig. 3). An

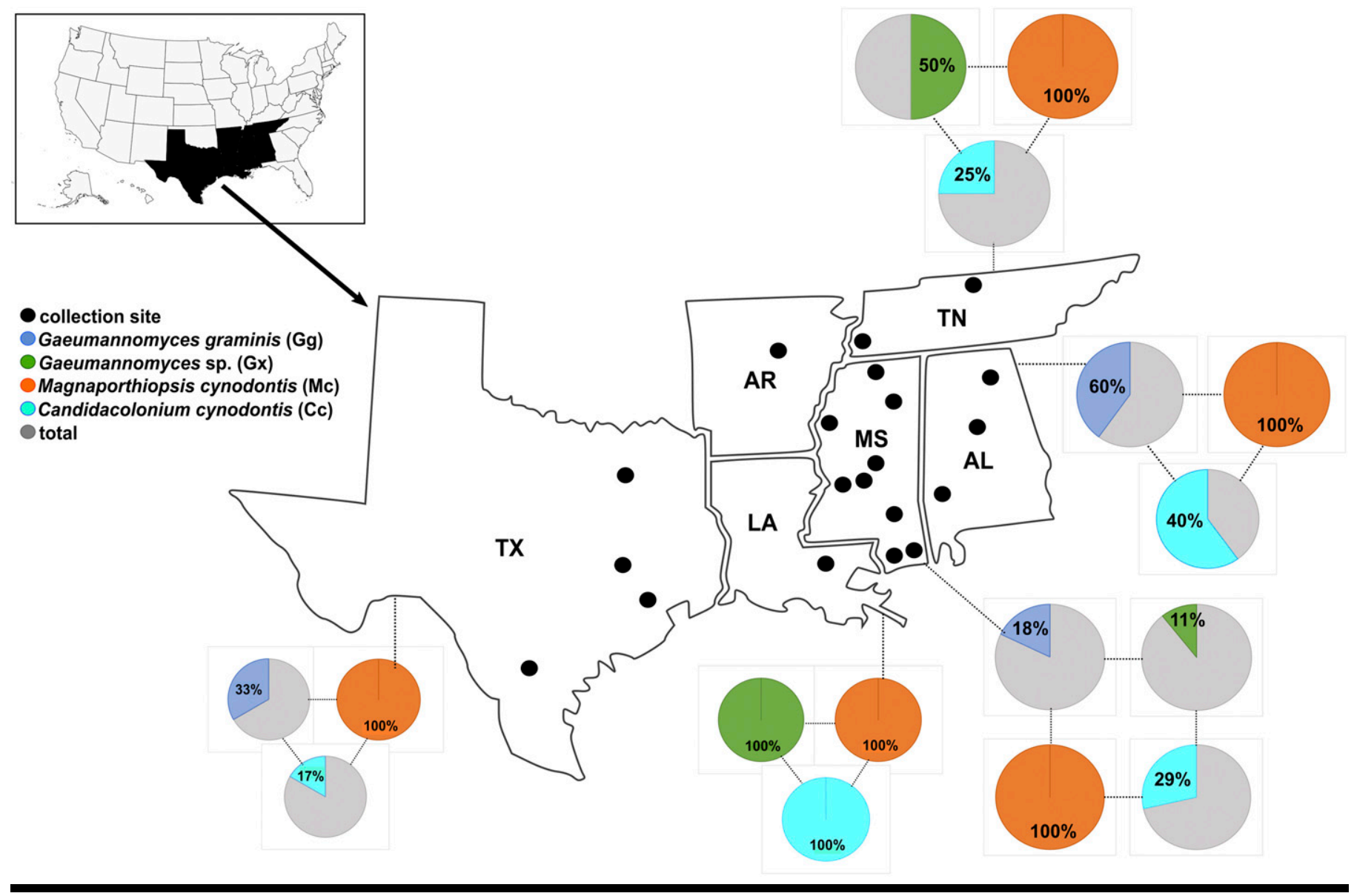

FIGURE 3

The southeastern United States with approximate site locations of sample collection and fungal species detected with the novel assays. Out of 37 samples, 36 were positive for at least one ectotrophic root-infecting (ERI) fungus. An ERI fungal complex was detected in 59\% of samples. Hybrid bermudagrass DNA was obtained from the Mississippi State University Plant Disease Diagnostic Laboratory (MSUPDDL). Whole plant samples from golf courses were sent to the MSUPDDL for examination. Total DNA was extracted from roots and tested using the multiplex qPCR assays to determine the presence of select ERIs. Pie charts represent the overall percentage of fungal presence in bermudagrass samples collected in each state. More than one sample was collected from the same golf course, with some coming from the same green and some from different greens. No more than six samples were analyzed from the same golf course. 
ERI fungal complex was detected in 59\% of samples, and of those, eight were coinfected with three ERI fungi and 14 were coinfected with two ERI fungi (Table 3). The total number of DNA copies of ERI fungi when detected in bermudagrass roots varied from very low for Gx and Mc (28,216 and 376,189, respectively) to very high for $\mathrm{Gg}$ and $\mathrm{Cc}(19,204,294$ and 10,070,346, respectively) when

\section{TABLE 3}

Validation of multiplex qPCR assays for identification of select ectotrophic root-infecting fung $i^{\mathrm{a}}$ associated with

hybrid bermudagrass roots. Samples were submitted to the Mississippi State University Plant Disease Diagnostic

Laboratory from six states in the southeastern United States in 2018.

qPCR results

\section{State \\ County/parish}

Host

Gg

Cc $\mathrm{M}$

AL

Jackson

AL Marshall

AL Marshall

AL Shelby

AL Shelby

AR Lonoke

LA

MS

MS

MS

MS

MS

MS

MS

MS

MS

MS

MS

MS

MS

MS

MS

MS

MS

MS

MS

MS

MS

TN

TN

TN

TX

TX

TX

TX

TX

TX
St. Tammany

Hancock

Harrison

Harrison

Harrison

Lamar

Lamar

Lamar

Madison

Madison

Madison

Madison

Madison

Madison

Madison

Oktibbeha

Panola

Rankin

Rankin

Rankin

Rankin

Washington

Madison

Madison

Shelby

Bexar

Dallas

Harris

Harris

Montgomery

Montgomery
Bermuda ${ }^{b}$

Bermuda $^{b}$

Bermuda $^{b}$

Bermuda $^{b}$

Bermuda $^{b}$

Bermuda $^{b}$

Bermuda $^{\mathrm{b}}$

TifEagle

Bermuda $^{\mathrm{b}}$

Bermuda $^{b}$

TifEagle

Tifgreen

Tifgreen

Tifgreen

Bermuda $^{b}$

Bermuda $^{b}$

Bermuda $^{b}$

Bermuda $^{\mathrm{b}}$

TifEagle

Bermuda $^{b}$

MiniVerde

TifEagle

Bermuda $^{b}$

Bermuda $^{b}$

Bermuda $^{\mathrm{b}}$

Bermuda $^{b}$

Bermuda $^{b}$

Champion

Champion

Champion

Champion

Bermuda

Champion

TifEagle

TifEagle

Champion

Champion

a Fungi: $\mathrm{Gg}=$ Gaeumannomyces graminis; $\mathrm{Gx}=$ Gaeumannomyces $\mathrm{sp}$.; $\mathrm{Mc}=$ Magnaporthiopsis cynodontis; and $\mathrm{Cc}=$ Candidacolonium cynodontis.

${ }^{\mathrm{b}}$ Cultivar unknown.

${ }^{c}$ Plus sign (+) indicates detection of select ectotrophic root-infecting fungi in hybrid bermudagrass root DNA.

compared with bermudagrass root DNA copies $(\sim 2,697,704)$. The number of DNA copies for Mc was constitutively lower, at least 14 times less compared with bermudagrass root DNA, and Gx resulted in 13 times less DNA copies when compared with bermudagrass root DNA $(P<0.0001)$ (Fig. 4). The number of DNA copies for $\mathrm{Gg}$ $(19,204,294)$ and Cc $(10,070,346)$ were significantly greater than the number of bermudagrass root DNA copies $(P<0.0001)$.

\section{Discussion}

This study reports the development and application of the first species-specific assays for detection and differentiation of $\mathrm{Gg}, \mathrm{Gx}$, $\mathrm{Mc}$, and $\mathrm{Cc}$, four important ERI fungi associated with BD in hybrid bermudagrasses. These ERI fungi share distinct characteristics of darkly pigmented runner hyphae, growth cessation structures, and with some species, simple or lobed hyphopodia (Landschoot 1993; Wetzel et al. 1996). Traditionally, the identity of ERI fungi is detected through microscopic examination of infected plant tissue and fungal isolation. These methods are time-intensive and may lead to erroneous results, because it is difficult to isolate more than one ERI fungus from infected root material. Traditional PCR techniques have been developed to differentiate ERI fungi once isolated from bermudagrass roots (Elliott et al. 1993; Freeman and Ward 2004; Rachdawong et al. 2002; Sadeghi et al. 2012; Ward and Akrofi 1994; Wetzel et al. 1996). However, in cases of coinfection, traditional PCR is not sensitive enough to differentiate fungal species. Our assays were capable of detecting and differentiating the select ERI species, even in bermudagrass root samples that were coinfected with two or more ERI fungi.

The assays were validated by testing hybrid bermudagrass samples from regional golf courses that were either asymptomatic or showed root rot associated with the presence of ERI fungi. Ninety-seven percent of hybrid bermudagrass samples from throughout the southeastern United States were colonized with at

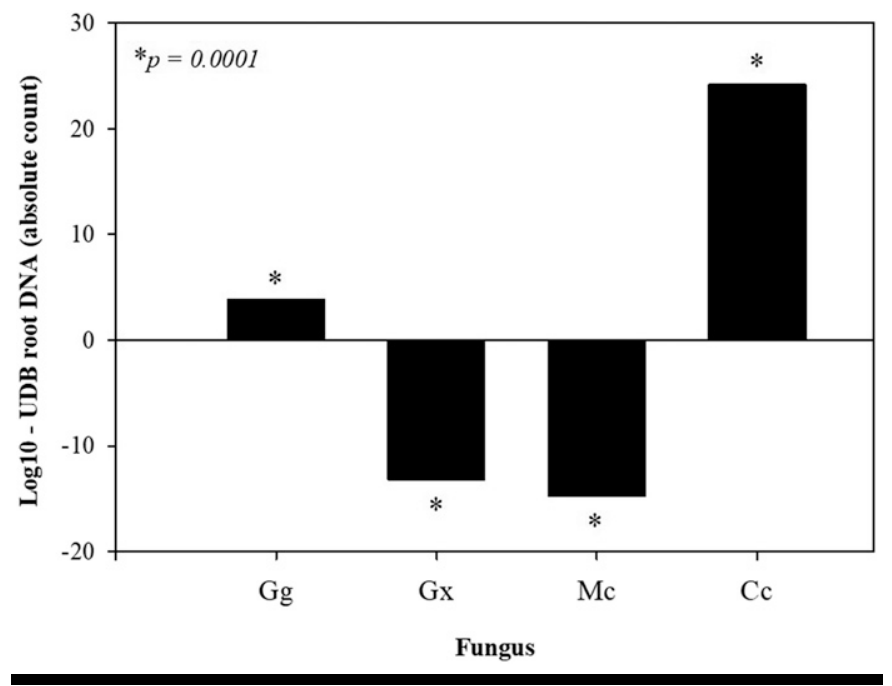

FIGURE 4

Total fungal versus bermudagrass DNA copies calculated based on plasmid standard curve. Magnaporthiopsis cynodontis (Mc) and Gaeumannomyces sp. (Gx) had less DNA copies when compared with bermudagrass root DNA (13 and 15 times less DNA, respectively); Candidacolonium cynodontis (Cc) had 24 and Gaeumannomyces graminis $(\mathrm{Gg})$ had 4 times more DNA than the bermudagrass root DNA. The high number of DNA copies for $\mathrm{Cc}$ and $\mathrm{Gg}$ in bermudagrass roots may reflect their virulence, whereas low copy numbers of Mc and Gx may indicate these two species as secondary pathogens within the ERI complex. 
least one ERI fungus positively identified with these assays. Considering the number of DNA copies of fungus versus bermudagrass root from golf course samples, $\mathrm{Gg}$ and $\mathrm{Cc}$ had significantly greater numbers when compared with root material. Pathogenicity experiments conducted by Vines (2015) suggest these two fungi were more aggressive when compared with Gx and Mc. The high number of DNA copies resulting from this study for Cc and Gg in bermudagrass roots may reflect their aggressiveness, and $\mathrm{Mc}$ and Gx may only serve as secondary pathogens within the ERI complex.

Several studies have reported in plant detection of plant pathogens using multiplex reactions (Bonants et al. 2019; Huang et al. 2019; Rojas et al. 2017). Our assays were based on LNA probes, which were vital to improving fungal detection. LNA probes are chimeric probes with select positions modified with LNAs. This modification is reported to enhance stability and mismatch discrimination during primer and template binding in PCR reactions (Ugozzoli et al. 2004). Due its sensitivity and specificity, this technology is particularly beneficial when applied to differentiate closely related species in PCR reactions (You et al. 2006). Several studies have applied this technology for diagnosis and quantification of plant viruses and nematodes (Madani et al. 2008; Ruiz-Ruiz et al. 2009). Considering the high similarities among ERI fungal species, the use of LNA probes was crucial to increase the specificity of our assays and improve species differentiation and detection.

The efficiency and accuracy of the assays were consistent for the detection of the selected ERI fungi in this study. The efficiencies between single and multiplex reactions were not different, proving the stability of and confidence in the results of these two detection settings. These results support the use of the multiplex assays as an early detection tool for identification of $\mathrm{Gg}, \mathrm{Gx}, \mathrm{Mc}$, and $\mathrm{Cc}$ in bermudagrass root samples. Moreover, the assays' specificity provides in-plant monitoring and facilitates rapid identification, because these fungi may be present at low quantities although the canopy of the bermudagrass is asymptomatic. In the long term, this molecular tool will be a great asset for golf course superintendents by preventing loss of putting green turf due to BD caused by the ERI fungal complex and also aid in future epidemiological studies.

\section{Acknowledgments}

The authors thank Kate Phillips for her technical assistance throughout the project and Clarissa Balbalian for providing the bermudagrass DNA samples. We are also grateful to Integrated DNA Technologies for the helpful technical assistance during design of primers and probes.

\section{Literature Cited}

Bonants, P., Griekspoor, Y., Houwers, I., Krijger, M., van der Zouwen, P., van der Lee, T. A., and van der Wolf, J. 2019. Development and evaluation of a triplex TaqMan assay and next-generation sequence analysis for improved detection of Xylella in plant material. Plant Dis. 103:645-655.

Clarke, B. B., and Gould, A. B. 1993. Turfgrass Patch Diseases Caused by Ectotrophic Root-Infecting Fungi. American Phytopathological Society, St. Paul, MN.

Dunn, O. J. 1961. Multiple comparisons among means. J. Am. Stat. Assoc. 56: 52-64.

Elliott, M. L. 1991. Determination of an etiological agent of bermudagrass decline. Phytopathology 81:1380-1384.

Elliott, M. L., Des Jardin, E. A., and Henson, J. M. 1993. Use of a polymerase chain reaction assay to aid in identification of Gaeumannomyces graminis var. graminis from different grass hosts. Phytopathology 83:414-418.

Elliott, M. L., and Landschoot, P. J. 1991. Fungi similar to Gaeumannomyces associated with root rot of turfgrasses in Florida. Plant Dis. 75:238-241.

Freeman, J., and Ward, E. 2004. Gaeumannomyces graminis, the take-all fungus and its relatives. Mol. Plant Pathol. 5:235-252.
Freeman, T. E., and Augustin, B. J. 1984. Bermudagrass Decline. Florida Cooperative Extension Service, Institute of Food and Agricultural Sciences, University of Florida, Gainesville, FL.

Huang, D., Yan, G., Gudmestad, N., Ye, W., Whitworth, J., Frost, K., Crow, W., and Hajihassani, A. 2019. Developing a one-step multiplex PCR assay for rapid detection of four stubby-root nematode species, Paratrichodorus allius, P. minor, P. porosus, and Trichodorus obtusus. Plant Dis. 103: 404-410.

Landschoot, P. J. 1993. Taxonomy and biology of ectotrophic root-infecting fungi associated with patch diseases of turfgrasses. Pages 41-71 in: Turfgrass Patch Diseases Caused by Ectotrophic Root-Infecting Fungi. B. B. Clarke and A. B. Gould, eds. American Phytopathological Society, St. Paul, MN.

Madani, M., Ward, L. J., and De Boer, S. H. 2008. Multiplex real-time polymerase chain reaction for identifying potato cyst nematodes, Globodera pallida and Globodera rostochiensis, and the tobacco cyst nematode, Globodera tabacum. Can. J. Plant Pathol. 30:554-564.

McCarty, L. B., and Lucas, L. T. 1989. Gaeumannomyces graminis associated with spring dead spot of bermudagrass in the southeastern United States. Plant Dis. 73:659-661.

Rachdawong, S., Cramer, C. L., Grabau, E. A., Stromberg, V. K., Lacy, G. H., and Stromberg, E. L. 2002. Gaeumannomyces graminis vars. avenae, graminis, and tritici identified using PCR amplification of avenacinase-like genes. Plant Dis. 86:652-660.

Rojas, J. A., Miles, T. D., Coffey, M. D., Martin, F. N., and Chilvers, M. I. 2017. Development and application of qPCR and RPA genus-and species-specific detection of Phytophthora sojae and P. sansomeana root rot pathogens of soybean. Plant Dis. 101:1171-1181.

Ruiz-Ruiz, S., Moreno, P., Guerri, J., and Ambrós, S. 2009. Discrimination between mild and severe Citrus tristeza virus isolates with a rapid and highly specific real-time reverse transcription-polymerase chain reaction method using TaqMan LNA probes. Phytopathology 99:307-315.

Sadeghi, L., Alizadeh, A., Safaie, N., and Jamali, S. H. 2012. Genetic diversity of Gaeumannomyces graminis var. tritici populations using RAPD and ERIC markers. J. Plant Pathol. Microbiol. 3:143.

Smiley, R. W., Dernoeden, P. H., and Clarke, B. B. 2005. Compendium of Turfgrass Diseases, 3rd Ed. American Phytopathological Society, St. Paul, $\mathrm{MN}$.

Tamura, K., Stecher, G., Peterson, D., Filipski, A., and Kumar, S. 2013. MEGA6: Molecular Evolutionary Genetics Analysis version 6.0. Mol. Biol. Evol. 30:2725-2729.

Turgeon, A. J. 2005. Turfgrass Management, 7th Ed. Pearson, Prentice Hall, Upper Saddle River, NJ.

Ugozzoli, L. A., Latorra, D., Pucket, R., Arar, K., and Hamby, K. 2004. Realtime genotyping with oligonucleotide probes containing locked nucleic acids. Anal. Biochem. 324:143-152.

Vines, P. L. 2015. Evaluation of ultradwarf bermudagrass cultural management practices and identification, characterization, and pathogenicity of ectotrophic root-infecting fungi associated with summer decline of ultradwarf bermudagrass putting greens. Thesis. Mississippi State University, Mississippi State, MS.

Vines, P. L., Hoffmann, F. G., Meyer, F., Allen, T. W., Luo, J., Zhang, N., and Tomaso-Peterson, M. 2020. Magnaporthiopsis cynodontis, a novel turfgrass pathogen with widespread distribution in the United States. Mycologia 112: $52-63$.

Ward, E., and Akrofi, A. Y. 1994. Identification of fungi in the Gaeumannomyces-Phialophora complex by RFLPs of PCR-amplified ribosomal DNAs. Mycol. Res. 98:219-224.

Wetzel, H. C., Dernoeden, P. H., and Millner, P. D. 1996. Identification of darkly pigmented fungi associated with turfgrass roots by mycelial characteristics and RAPD-PCR. Plant Dis. 80:359-364.

White, T. J., Bruns, T., Lee, S. J. W. T., and Taylor, J. 1990. Amplification and direct sequencing of fungal ribosomal RNA genes for phylogenetics. Pages 315-322 in: PCR Protocols: A Guide to Methods and Applications. Academic Press, San Diego, CA.

You, Y., Moreira, B. G., Behlke, M. A., and Owczarzy, R. 2006. Design of LNA probes that improve mismatch discrimination. Nucleic Acids Res. 34:e60.

Young, J. R., Tomaso-Peterson, M., De la Cerda, K., and Wong, F. P. 2010. Two mutations in $\beta$-tubulin 2 gene associated with thiophanate-methyl resistance in Colletotrichum cereale isolates from creeping bentgrass in Mississippi and Alabama. Plant Dis. 94:207-212.

Zhang, N., Zhao, S., and Shen, Q. 2011. A six-gene phylogeny reveals the evolution of mode of infection in the rice blast fungus and allied species. Mycologia 103:1267-1276. 